Article

\title{
Short-Term High-Starch, Low-Protein Diet Induces Reversible Increase in $\beta$-cell Mass Independent of Body Weight Gain in Mice
}

\author{
Atsushi Masuda ${ }^{1}$, Yusuke Seino ${ }^{1, *}$, Masatoshi Murase ${ }^{2}$, Shihomi Hidaka ${ }^{1}$, Megumi Shibata ${ }^{1}$, \\ Takeshi Takayanagi ${ }^{1}$, Yoshihisa Sugimura ${ }^{1}$, Yoshitaka Hayashi ${ }^{3}{ }^{[D}$ and Atsushi Suzuki ${ }^{1}$ (D) \\ 1 Department of Endocrinology and Metabolism, Fujita Health University, Graduate School of Medicine, \\ Toyoake 470-1192, Japan; a-masuda@fujita-hu.ac.jp (A.M.); sakai220@fujita-hu.ac.jp (S.H.); \\ megumi03@fujita-hu.ac.jp (M.S.); haratake@fujita-hu.ac.jp (T.T.); sugiyosi@fujita-hu.ac.jp (Y.S.); \\ aslapin@fujita-hu.ac.jp (A.S.) \\ 2 Departments of Endocrinology and Diabetes, Toyota Memorial Hospital, Toyota 471-8513, Japan; \\ murase-m@med.nagoya-u.ac.jp \\ 3 Department of Endocrinology, Research Institute of Environmental Medicine, Nagoya University, \\ Nagoya 467-8601 Japan; hayashiy@riem.nagoya-u.ac.jp \\ * Correspondence: seinoy@fujita-hu.ac.jp; Tel.: +81-562-93-9242; Fax: +81-562-95-1879
}

Received: 3 April 2019; Accepted: 8 May 2019; Published: 10 May 2019

\begin{abstract}
Long-term exposure to a high starch, low-protein diet (HSTD) induces body weight gain and hyperinsulinemia concomitantly with an increase in $\beta$-cell mass (BCM) and pancreatic islets number in mice; however, the effect of short-term exposure to HSTD on BCM and islet number has not been elucidated. In the present study, we investigated changes in body weight, plasma insulin levels, BCM and islet number in mice fed HSTD for 5 weeks followed by normal chow (NC) for 2 weeks. BCM and islet number were increased in mice fed HSTD for 5 weeks compared with those in mice fed NC. On the other hand, mice fed HSTD for 5 weeks followed by NC for 2 weeks (SN) showed decreased BCM and insulin levels, compared to mice fed HSTD for 7 weeks, and no significant differences in these parameters were observed between SN and the control NC at 7 weeks. No significant difference in body weight was observed among HSTD, NC and SN fed groups. These results suggest that a high-starch diet induces an increase in BCM in a manner independent of body weight gain, and that 2 weeks of NC feeding is sufficient for the reversal of the morphological changes induced in islets by HSTD feeding.
\end{abstract}

Keywords: carbohydrate; $\beta$-cell mass; islet number; insulin; dietary intervention

\section{Introduction}

Insulin is secreted from pancreatic $\beta$-cells, and plays an important role in glucose metabolism. Glucose stimulates insulin secretion directly and indirectly through incretins such as glucose-dependent insulinotropic polypeptide (GIP) and glucagon-like peptide-1 (GLP-1) [1]. Both insulin and GIP contribute to the promotion of fat deposition in adipose tissue [2-4]. Indeed, any blockade of the GIP signal and/or hyperinsulinemia is a protection from high-fat diet (HFD)-induced obesity in mice [2-6]. On the other hand, we previously reported that both wild-type (WT) and GIP receptor-deficient (GiprKO) mice fed a high-starch, low-protein diet (HSTD), show a body weight gain, compared with those fed normal chow (NC), indicating that HSTD induces obesity in a manner independent of the GIP signal [5]. In addition, glucose-induced insulin secretion (GIIS) from isolated islets is enhanced in WT and GiprKO-fed HSTD, compared with those in WT and GiprKO-fed NC or a moderate-fat diet 22 weeks after intervention of the diets [5]. 
These results suggest that the enhanced insulin secretion participates in body weight gain in mice fed HSTD. The increase of pancreatic $\beta$-cell mass (BCM) and islet number contributes to the augmentation of insulin secretion. Indeed, BCM and islet number are increased in WT mice fed HSTD, compared with those in WT mice fed NC 22 weeks after intervention of the diets [7]. It is reported that BCM is increased in obese and/or insulin-resistant rodents and humans $[8,9]$. Therefore, it is unclear whether BCM and islet number in WT mice fed HSTD for 22 weeks are increased, compared with those in mice fed NC due to excess supplementation of glucose, the final product of starch, or to obesity and decrease in insulin sensitivity.

In the present study, we find that BCM and islet number are increased in WT mice fed HSTD for 5 weeks, compared with those fed $\mathrm{NC}$, before the difference in body weight is apparent, and that the increase of BCM and islet number is reversible 2 weeks after switching from HSTD to NC, regardless of the change of body weight.

\section{Materials and Methods}

\subsection{Animals and Diets}

Eight-week-old male C57BL/6J wild-type (WT) mice were obtained from CLEA Japan (Osaka, Japan) and housed in a room under a standard 12:12-h light/dark cycle with free access to food and water. WT mice were divided into two groups: Mice fed normal chow (NC) (starch 58\%, protein 29\%, soy oil 13\% of total energy; CLEA Japan, Osaka, Japan) and high starch, low-protein diet (HSTD) (starch $74 \%$, protein $13 \%$, soy oil $13 \%$ of total energy; CLEA Japan, Osaka, Japan), as previously reported $[5,7,10,11]$. CE-2 (CLEA, Japan, Osaka, Japan) was used for NC (carbohydrate 58\%, protein $29 \%$, fat consisting of soy oil $13 \%$ of total energy, the carbohydrate consisting of starch). HSTD (starch $74 \%$, protein $13 \%$, soy oil $13 \%$ of total energy) was produced by adding $51 \mathrm{~g}$ CE- 2 to $46 \mathrm{~g}$ starch and $3.1 \mathrm{~g}$ soy oil. NC diet was $3.87 \mathrm{kcal} / \mathrm{g}$, and HSTD diet was $3.43 \mathrm{kcal} / \mathrm{g}$. Mice were fed for 3, 5 or 7 weeks, and then analyzed independently. Data on 5 weeks of intervention were also obtained from mice in which islets were isolated. All procedures were carried out according to a protocol approved by the Institutional Animal Care and Use Committee of Fujita Health University.

\subsection{Intraperitoneal Glucose Tolerance Test (IPGTT) and Insulin Tolerance Test (ITT)}

IPGTT was performed 5 or 7 weeks after intervention of the diets. After $16 \mathrm{~h}$ of food deprivation, glucose $(2 \mathrm{~g} / \mathrm{kg})$ was administrated to mice intraperitoneally. ITT was performed 5 or 7 weeks after intervention of diets. After $6 \mathrm{~h}$ of food deprivation, insulin $(0.75 \mathrm{U} / \mathrm{kg})$ was injected intraperitoneally to mice. None of the mice received both IPGTT and ITT.

\subsection{Plasma Biochemical Analyses}

Blood was collected from the tip of the tail. Blood glucose levels were measured with Antsense Duo (Horiba, Kyoto, Japan). Blood samples were centrifuged (13,500 rpm, $10 \mathrm{~min}, 4^{\circ} \mathrm{C}$ ) twice, and the collected plasma samples were stored at $-80^{\circ} \mathrm{C}$ until analysis. Plasma insulin levels were measured using a Mouse Insulin ELISA Kit (Morinaga Institute of Biological Science, Kanagawa, Japan) as previously reported [7].

\subsection{Isolation of Ribonucleic Acid (RNA) and Quantitative Real-Time Reverse Transcription Polymerase Chain Reaction (RT-PCR)}

Pancreata were perfused with collagenase $4.5 \mathrm{mg}$ (cat.112490020001; Roche, Basel, Switzerland) in 3 mL RPMI medium (1×)1640 (11875-093; gibcl, Tokyo, Japan). The pancreata were removed and collected in tubes containing $5 \mathrm{~mL}$ HBSS-HEPES( $\mathrm{pH} 7.2)$, and placed in a water bath $\left(37^{\circ} \mathrm{C}\right)$ for $11.5 \mathrm{~min}$. Samples with KRB (pH7.4 0.1\%BSA) were then centrifuged (1000 rpm, $2 \mathrm{~min}, 4^{\circ} \mathrm{C}$ ) twice. The sediment was blended with 8 mL Histopaque 1119 (11191; SIGMA, St. Louis, MO, USA) and 
added to a $4 \mathrm{~mL}$ mixture of $2 \mathrm{~mL}$ Histopaque 1119 and 2 mL Histopaque 1077 (10771; SIGMA, St. Louis, MO, USA) together with 4mL KRB (pH7.4 0.1\%BSA).

The adulterant was then centrifuged ( $\left.1000 \mathrm{rpm}, 25 \mathrm{~min}, 4^{\circ} \mathrm{C}\right)$, the supernatant was collected and centrifuged again $\left(1000 \mathrm{rpm}, 2 \mathrm{~min}, 4^{\circ} \mathrm{C}\right)$, and the islets were picked up. Total RNA was collected from isolated islets using the RNeasy Plus Kit (Qiagen, Tokyo, Japan) and complementary Deoxyribonucleic Acid (cDNA) synthesis was performed, as previously reported $[5,7,12]$. The polymerase chain reaction (PCR) method for thermal cycling was used with an Applied Biosystems by the $2^{\Delta \Delta C T}$ method. Each PCR reaction mixture $(25 \mu \mathrm{L})$ contained 100 ng genomic DNA, SYBR qPCR Mix 12.5uL (Toyobo, Saitama, Japan), $3 \mu \mathrm{M}$ of each primer $2.5 \mathrm{uL}$, Rob Reference Dye $0.5 \mathrm{uL}$ (Toyobo, Saitama, Japan), and DEPC water $4.5 \mathrm{uL}$. The qPCR was performed with an initial polymerase activation step at $95^{\circ} \mathrm{C}$ for $1 \mathrm{~min}$, followed by 40 cycles of denaturation $\left(95^{\circ} \mathrm{C}\right.$ for $\left.15 \mathrm{~s}\right)$ and annealing/extension $\left(60^{\circ} \mathrm{C}\right.$ for $45 \mathrm{~s})$. The primer sequence is shown in Table 1 . The expression levels of mRNA were normalized by those of $\beta$-actin.

Table 1. Primers used for quantitative real-time polymerase chain reaction (PCR).

\begin{tabular}{ccc}
\hline Gene & Forward Primer $\left(\mathbf{5}^{\prime}\right.$ to $\mathbf{3}^{\prime} \mathbf{)}$ & Reverse $\mathbf{P r i m e r}\left(\mathbf{5}^{\prime}\right.$ to $\mathbf{3}^{\prime} \mathbf{)}$ \\
\hline Bactin & CATCCGTAAAGACCTCTATGCCAAC & ATGGAGCCACCGATCCACA \\
cyclinA2 & TCCTTGCTTTTGACTTGGCT & ATGACTCAGGCCAGCTCTGT \\
cyclinD1 & GCCGAGAAGTTGTGCATCTA & TCACCAGAAGCAGTTCCATTT \\
cyclinD2 & CACCGACAACTCTGTGAAGC & TCCACTTCAGCTTACCCAACA \\
Ins1 & CCTTAGTGACCAGCTATAATCAGAG & AGATGCTGTTTGACAAAAGCC \\
Ins2 & AGCCCTAAGTGATCCGCTACA & AAGGTGCTGCTTGACAAAAGCC \\
IRS2 & TCCAGGCACTGGAGCTTT & GGCTGGTAGCGCTTCACT \\
\hline
\end{tabular}

\subsection{Immunohistochemistry and Morphological Analyses}

The pancreata of WT mice were fixed with $4 \%$ paraformaldehyde and embedded in paraffin. Serial sections of $4 \mu \mathrm{m}$ thickness were cut from each paraffin block at $200 \mu \mathrm{m}$ intervals and deparaffinized as previously reported $[7,12]$. The sections were incubated overnight at $4{ }^{\circ} \mathrm{C}$ with primary antibodies against insulin (1:300; ab7842; Abcam, Cambridge, MA, USA), followed by 90 minutes incubation in Alexa Fluor-conjugated secondary antibody (1:500; A11074; Alexa Fluor 546; Invitrogen, Grand Island, NY, USA) at room temperature. DAPI solution (1:2000; 340-07971; Dojindo, Kumamoto, Japan) was used at room temperature for $30 \mathrm{~min}$. The total area of insulin-positive cells ( $\beta$-cells) and the number of islets were determined with BZ-9000 fluorescent microscope system (Keyence, Osaka, Japan), as previously reported [7].

\subsection{Statistical Analysis}

Data are expressed as means \pm SEM. Statistical significance of the difference between two groups was evaluated by Student's $t$-test, and that for multiple comparisons was investigated by ANOVA using GraphPad Prism 7 for Windows (GraphPadSoftware, La Jolla, CA, USA) [7]. $p<0.05$ was considered statistically significant.

\section{Results}

\subsection{Pancreatic Islet Number and BCM Were not Increased in HSTD-Fed Mice 3 Weeks after Intervention}

We first examined body weight, blood glucose levels and plasma insulin levels in WT mice fed NC or HSTD 3 weeks after intervention of diet. Body weight, blood glucose levels and plasma insulin levels under ad libitum-fed condition were not different between NC-fed mice and HSTD-fed mice (Figure 1A-C). Neither islet number nor BCM was different between NC-fed mice and HSTD-fed mice (Figure 1D-F). 

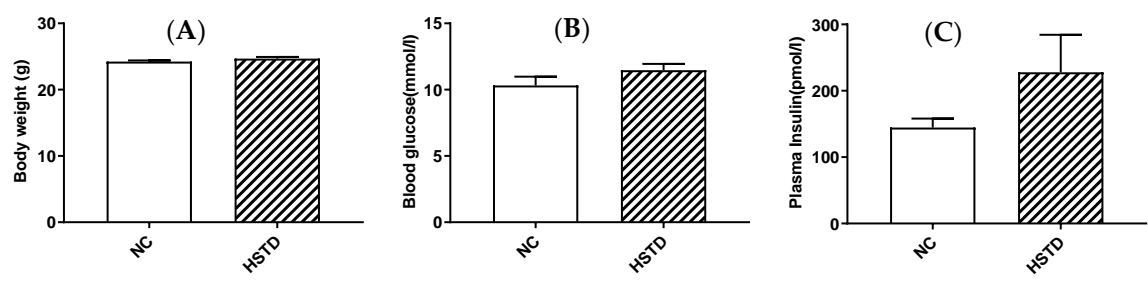

(D)

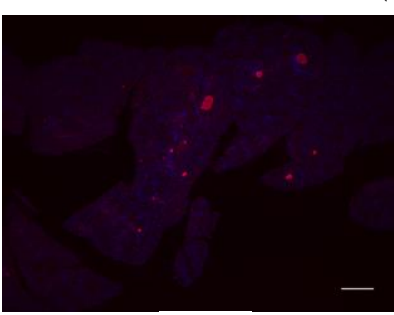

NC

(E)

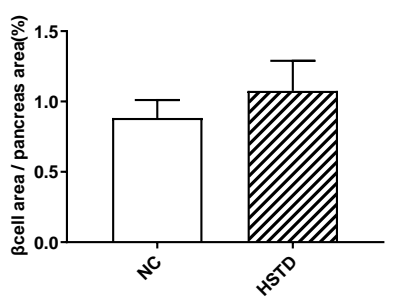

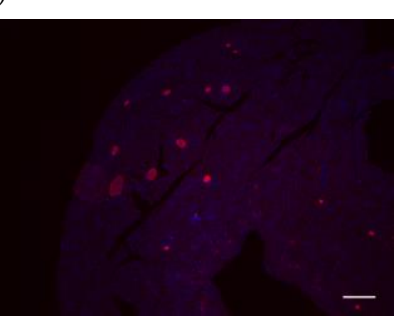

HSTD

(F)

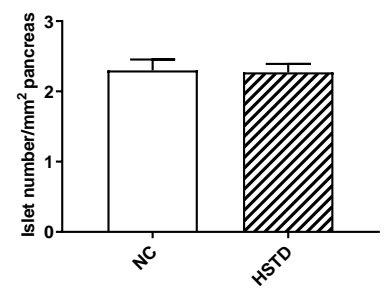

Figure 1. Body weight, metabolic parameters, $\beta$-cell mass (BCM), and islet number 3 weeks after intervention of diet in mice. (A) Body weight, (B) blood glucose and (C) plasma insulin levels under ad libitum fed condition. Normal chow (NC)-fed mice (white bar; $n=8$ ); high starch, low-protein diet (HSTD)-fed mice (white hatched bar; $n=8$ ) (D) The pancreatic section was stained with the antibody to insulin (red) and 40,6-diamidino-2-phenylindole (blue). Scale bars, $300 \mu \mathrm{m}$. (E) $\beta$-Cell area relative to pancreas area. (F) Number of islets relative to pancreas area. Statistical comparisons were done by unpaired Student's $t$ test in $(\mathbf{A}-\mathbf{C}, \mathbf{E}, \mathbf{F})$. Data represent means \pm SEM.

\subsection{Plasma Insulin Levels Were Elevated in HSTD-Fed Mice 5 Weeks after Intervention}

We next investigated body weight, blood glucose levels and plasma insulin levels in WT mice fed NC or HSTD 5 weeks after intervention of diet. Body weight and blood glucose levels under ad libitum-fed condition were not different between NC-fed mice and HSTD-fed mice, but plasma insulin levels in HSTD-fed mice under ad libitum-fed condition were significantly higher compared with those in NC-fed mice (Figure 2A-C). To evaluate the insulin secretory response to glucose, IPGTT was performed 5 weeks after intervention of diet. Blood glucose levels and plasma insulin levels during IPGTT were not different between mice fed NC and HSTD (Figure 2D,E). We then conducted ITT to estimate insulin sensitivity in NC-fed and HSTD-fed mice 5 weeks after intervention of diet. Blood glucose levels in comparison to 0 min were significantly lower in mice fed HSTD, compared with those in mice fed NC (Figure 2F). 
(A)

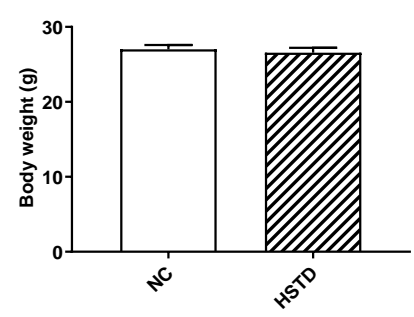

(D)

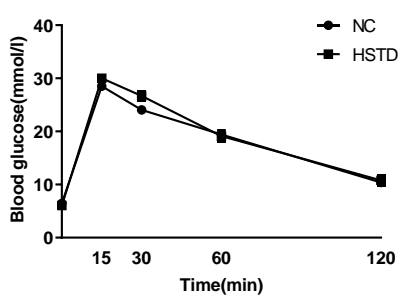

(B)

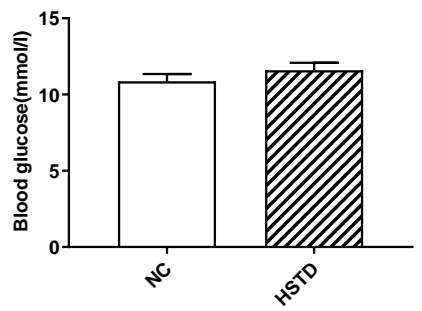

(E)
(C)

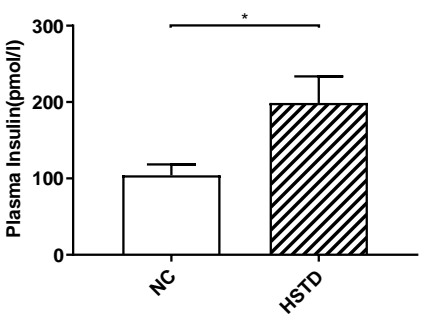

(F)
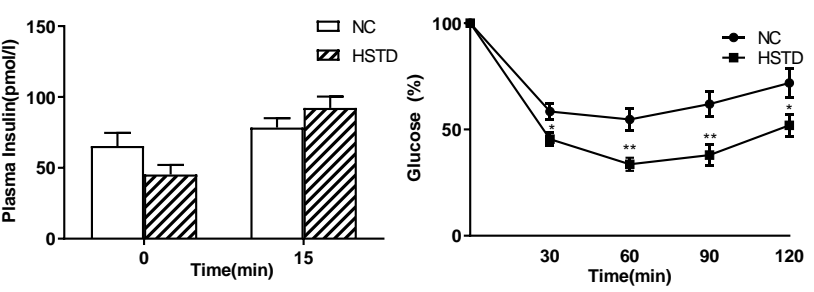

Figure 2. Body weight, metabolic parameters and evaluation of glucose tolerance and insulin sensitivity 5 weeks after intervention of diet in mice. (A) Body weight, (B) blood glucose and (C) plasma insulin levels under ad libitum fed condition. NC-fed mice (white bar; $n=8$ ); HSTD-fed mice (white hatched bar; $n=7) * p<0.05$ (D) Blood glucose levels and (E) plasma insulin levels during IPGTT in NC-fed mice (black circle and white bar; $n=11$ ) and HSTD-fed mice (black square and white hatched bar; $n=11$ ). (F) Blood glucose levels during ITT in comparison to $0 \mathrm{~min}$ in NC-fed mice (black circle; $n=12$ ) and HSTD-fed mice (black square; $n=9)\left({ }^{*} p<0.05,{ }^{* *} p<0.01\right.$ compared to NC at indicated time). Statistical comparisons were done by unpaired Student's $t$ test in (A-C) and multiple $t$ tests in (D-F). Correction for multiple comparisons was performed by using the Holm- Šidák method. Data represent means $\pm \mathrm{SEM}$.

\subsection{Pancreatic Islet Number and BCM Were Increased in HSTD-Fed Mice 5 Weeks after Intervention}

To assess the effect of a high-starch diet on pancreatic islets, we compared the morphology of islets in mice fed NC and HSTD 5 weeks after intervention of diet. Both islet number and BCM were significantly increased in mice fed HSTD, compared with those in mice fed NC (Figure 3A-C).

We then analyzed the gene expression levels in islets of NC-fed and HSTD-fed mice 5 weeks after intervention of diet. The expression levels of cyclin $A 2$ and insulin receptor substrate-2 (Irs2) mRNA were significantly higher in the islets of HSTD-fed mice, compared with those in the islets of NC-fed mice (Figure 3D). 
(A)

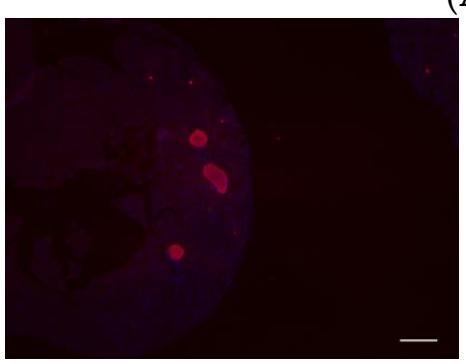

NC

(B)

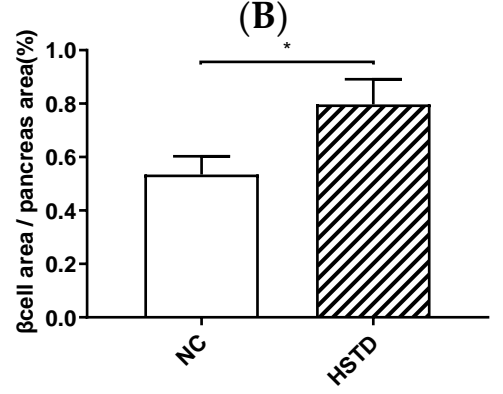

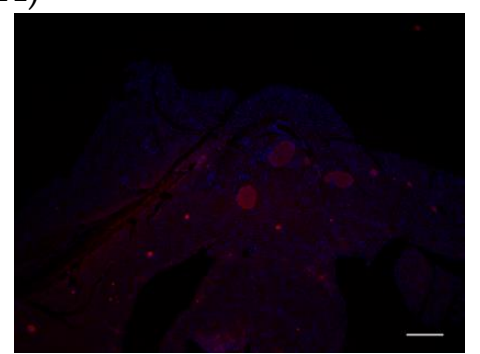

HSTD

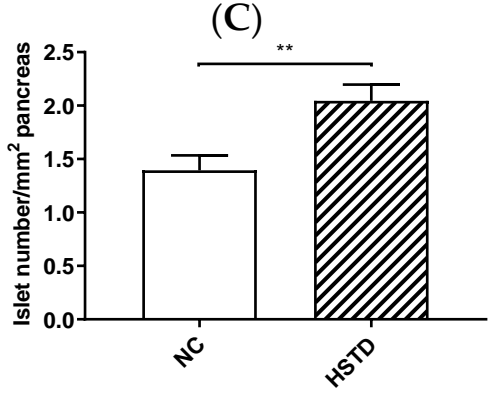

(D)

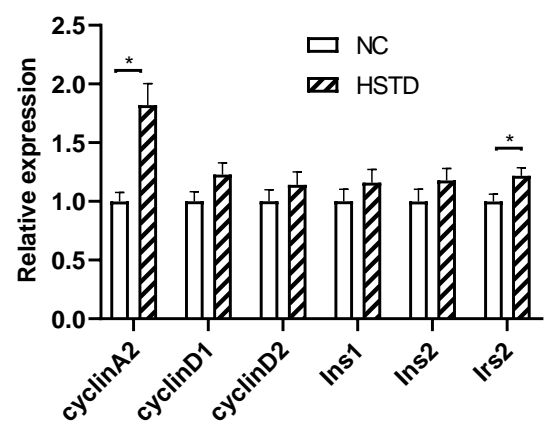

Figure 3. BCM, islet number and mRNA expression levels of islets 5 weeks after intervention of diet in mice. (A) The pancreatic section was stained with the antibody to insulin (red) and 40,6-diamidino-2-phenylindole (blue). Scale bars, $300 \mu \mathrm{m}$. (B) $\beta$-Cell area relative to pancreas area. (C) Number of islets relative to pancreas area. (D) mRNA expression levels of the indicated genes in isolated islets of mice fed NC (white bar; $n=16$ ) or HSTD (white hatched bar; $n=18$ ) 5 weeks after intervention of diet. Statistical comparisons were done by unpaired Student's $t$ test in $(\mathbf{B}, \mathbf{C})$ and multiple $t$ tests in (D). Correction for multiple comparisons was performed by using the Holm-Šidák method. Data represent means \pm SEM. ${ }^{*} p<0.05,{ }^{* *} p<0.01$.

\subsection{Switching from HSTD to NC Decreased Pancreatic Islet Number and BCM}

Mice were divided into three groups (Figure 4A). (1) NC group: Mice fed NC for 7 weeks (2) HSTD group: Mice fed HSTD for 7 weeks and (3) SN group: Mice fed HSTD for 5 weeks, and then fed NC for 2 weeks. We examined body weight, blood glucose levels and plasma insulin levels under ad libitum-fed condition 7 weeks after intervention of diet. Body weight and blood glucose levels were not different among the three groups (Figure 4B,C). Plasma insulin levels were significantly higher in HSTD group, compared with those in NC group and SN group, and were not different between NC group and SN group (Figure 4D). IPGTT or ITT was performed 7 weeks after intervention of diet. Blood glucose levels were not different among the three groups during IPGTT (Figure 4E).

No significant difference in blood glucose levels in comparison to 0 min during ITT was observed among the three groups, except for the levels $60 \mathrm{~min}$ after insulin administration. Blood glucose levels 
in comparison to $0 \mathrm{~min}$ in SN and HSTD groups were significantly lower, compared to the NC group at $60 \mathrm{~min}$ after insulin administration (Figure 4F). We then investigated whether switching from HSTD to NC affected the morphology of islets independent of body weight and blood glucose levels. Both islet number and BCM in HSTD group were significantly increased, compared with those in NC and SN group, and were not different between NC and SN group (Figure 4G-I).

(A)

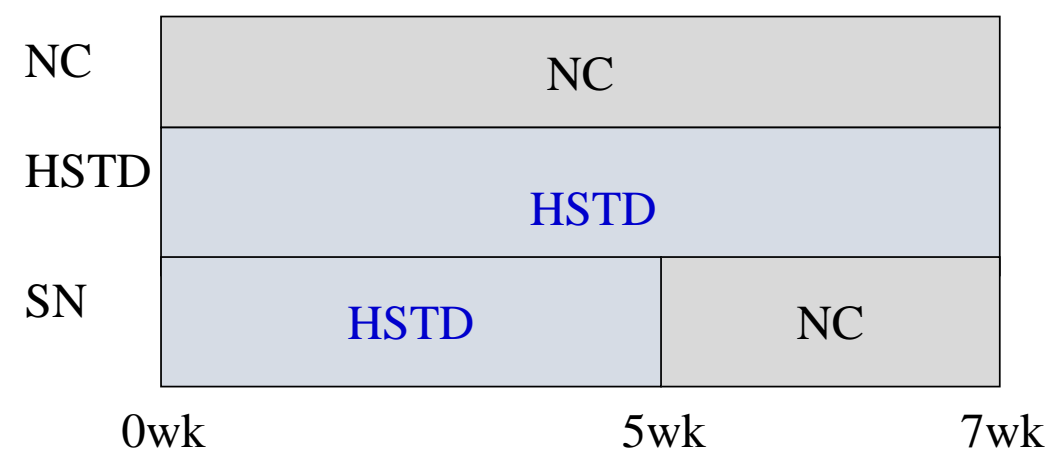

(B)

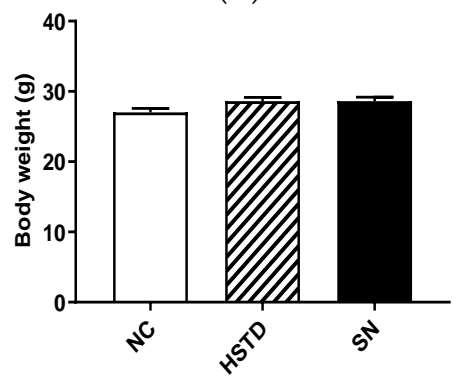

(E)

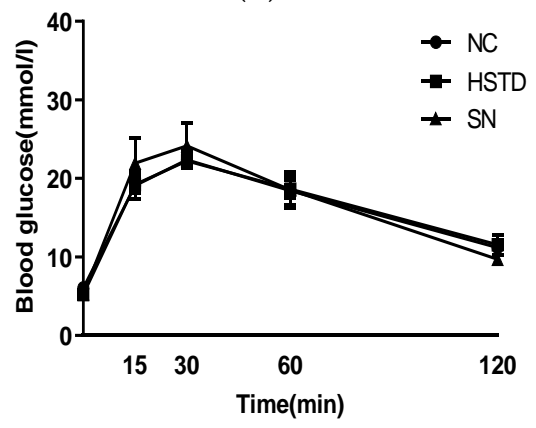

(C)
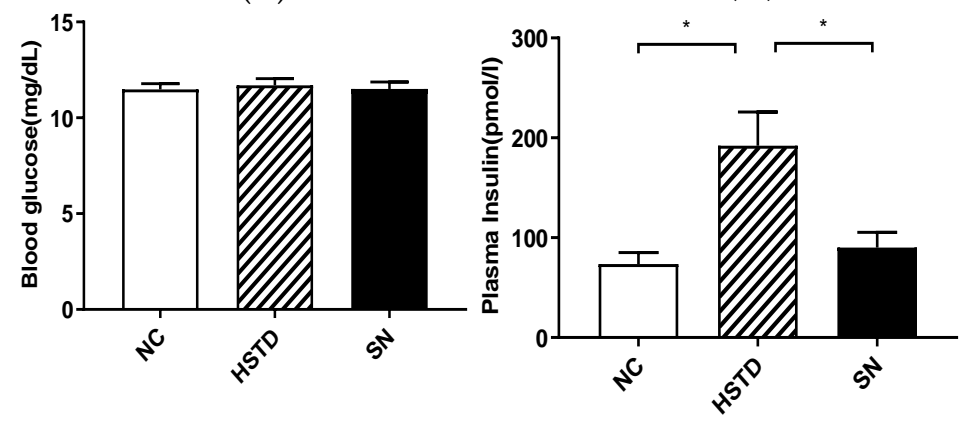

(F)

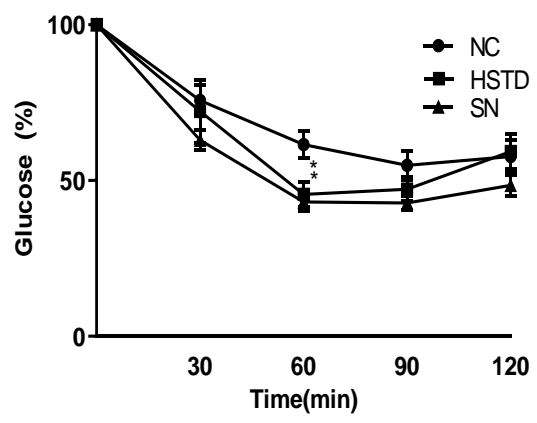

Figure 4. Cont. 
(G)

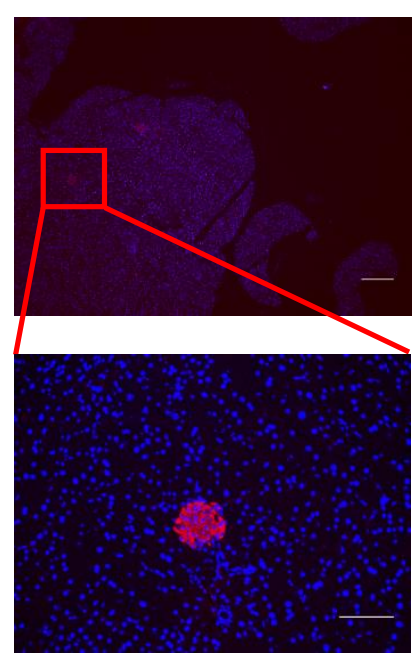

HSTD

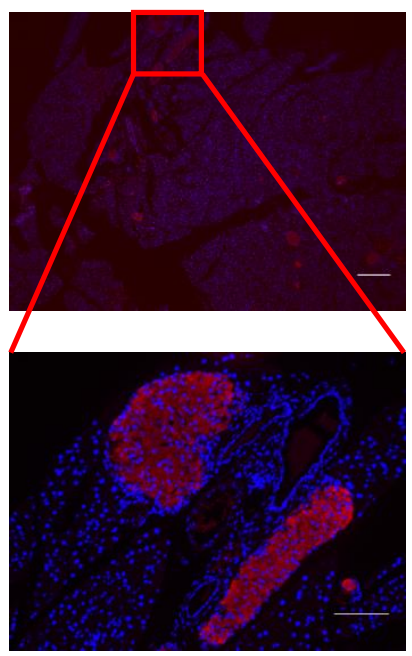

SN

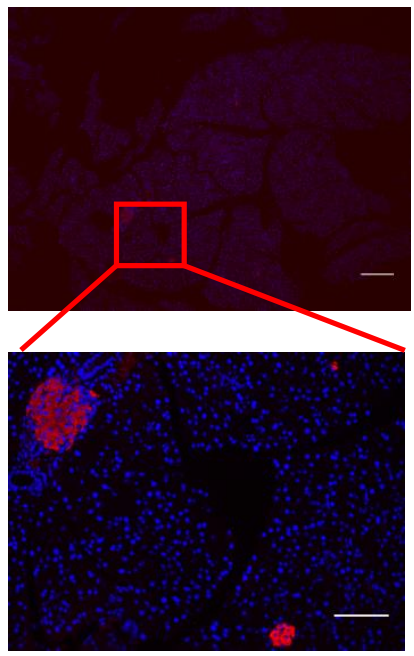

$(\mathbf{H})$

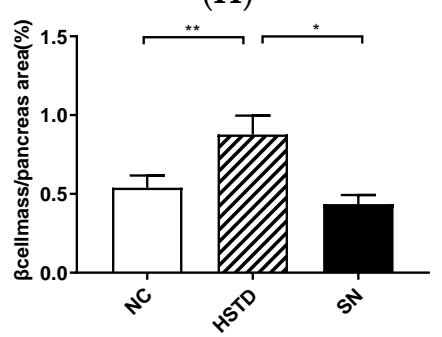

(I)

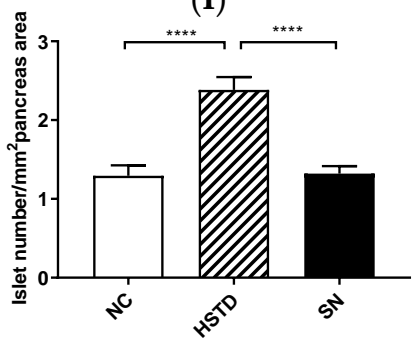

Figure 4. Protocol of this study and the comparison of body weight, metabolic parameters, and morphological analysis of islets between NC group, HSTD group and also mice fed HSTD for 5 weeks followed by NC for 2 weeks (SN) group, 7 weeks after intervention of diet in mice. (A) Study design. NC group: Mice fed NC for 7 weeks. HSTD group: Mice fed HSTD for 7 weeks. SN group: Mice fed HSTD for 5 weeks and then fed NC for 2 weeks. (B) Body weight, (C) blood glucose and (D) plasma insulin levels under ad libitum fed condition. NC group (white bar; $n=8$ ), HSTD group (white hatched bar; $n=8$ ) and SN group (black bar; $n=8$ ). (E) Blood glucose during IPGTT in NC group (black circle and white bar; $n=8$ ), HSTD group (black square and white hatched bar; $n=7$ ) and SN group (black triangle and black bar; $n=7$ ). (F) Blood glucose levels during ITT in comparison to 0 min NC group (black circle; $n=8$ ), HSTD group (black square; $n=8$ ) and SN group (black triangle; $n=8)$. $\left({ }^{*} p<\right.$ 0.05 compared to NC at indicated time). (G) The pancreatic section was stained with the antibody to insulin (red) and 40,6-diamidino-2-phenylindole (blue). Scale bars, $300 \mu \mathrm{m}$. (H) $\beta$-Cell area relative to pancreas area and (I) number of islets relative to pancreas area. NC group (white bar; $n=12$ ), HSTD group (white hatched bar; $n=12$ ) and SN group (black bar; $n=12$ ). Statistical comparisons were done by one-way ANOVA, with Tukey's multiple-comparison test in (B-D,H,I), and two-way ANOVA with Tukey's multiple-comparison test in (E,F). Data represent means \pm SEM. ${ }^{*} p<0.05,{ }^{* *} p<0.01,{ }^{* * * *} p<$ 0.0001 .

\section{Discussion}

In the present study, we show that BCM and islet number in mice fed HSTD for 5 weeks was increased, compared with that in mice fed NC, before the difference of blood glucose levels and body weight appeared, and that switching from HSTD to NC for two weeks reduced BCM and islet number, independent of any body weight change. Although plasma insulin levels in mice fed HSTD were significantly increased, compared to those in mice fed NC under ad libitum condition, insulin sensitivity evaluated by ITT was increased in HSTD-fed mice, compared to that in NC-fed mice. 
Continuous intravenous infusion of glucose or fat increases BCM in rodents [13-16]. Although there are many reports that analyze BCM in mice fed a high-fat diet (HFD), the morphology of islets in mice fed the high-starch diet has not been elucidated. Overnutrition, such as in HFD, induces obesity, together with a decrease of insulin sensitivity. Under these conditions, insulin demand is increased to sustain glucose homeostasis, and BCM is increased [17-19]. The morphology of islets and glucose metabolism in mice exposed to short-term HFD has been well investigated, as obesity and insulin resistance affects $B C M$, and it is not known whether excessive fat intake itself or obesity and/or insulin resistance increases BCM in mice under long-term exposure to HFD.

In mice fed HFD, body weight, blood glucose and plasma insulin levels are higher, and glucose intolerance is apparent, but insulin sensitivity evaluated by ITT is not decreased, compared to that in mice fed NC within 1 week of intervention of the diets [19-22]. In mice fed HFD for 1 week, $\beta$-cell proliferation is increased, with or without an increase of $B C M$, compared to that in mice fed NC [19-22]. These results suggest that the increase of BCM by HFD is induced before a decrease of insulin sensitivity. Enhanced expression levels of the genes involved in the cell cycle in islets depends on the term of exposure to HFD. The expression levels of cyclin D1 and cyclin D2 mRNA in islets in liver-specific insulin receptor-deficient mice, which show a decrease in insulin sensitivity, are increased, and it has been demonstrated that cyclin D2 contributes to the increase of BCM in these mice [23]. Indeed, the expression levels of cyclin D1 and cyclin D2 mRNA in islets of mice fed HFD for 8 or 20 weeks, which show a decrease in insulin sensitivity evaluated by ITT, were higher than those in islets of mice fed NC $[18,19]$. However, in mice fed HFD for 1 week, which do not display a decrease of insulin sensitivity, the expression levels of cyclin A2, but not cyclin D1 and cyclin D2, mRNA in islets are increased [19-22]. In our previous study, we found that BCM and the number of islets is increased in mice fed HSTD for 22 weeks, which show obesity and hyperglycemia and hyperinsulinemia, and that the expression levels of cyclin D1 and cyclin D2 mRNA in islets are increased in these mice [7]. On the other hand, in the present study, we show that BCM and the number of islets is increased in mice fed HSTD for 5 weeks, in which insulin sensitivity evaluated by ITT is not decreased, and that the expression levels of cyclin A2 mRNA, but not those of cyclin D1 and cyclin D2, mRNA are higher in islets of these mice, compared with those in mice fed NC. These results are similar to the previous experiments in mice exposed to short-term HFD. However, BCM and the number of islets in mice fed HSTD are increased before glucose tolerance and change in body weight appears, unlike those in mice fed NC. These results differ from those in mice exposed to short-term HFD. Plasma insulin levels in HSTD-fed mice under the ad libitum-fed condition were significantly higher compared with those in NC-fed mice, even though insulin sensitivity in peripheral organs, such as skeletal muscle and/or adipose tissue, was increased in HSTD-fed mice after 5 weeks intervention of diet. Whether or not insulin sensitivity is decreased in liver of HSTD-fed mice and/or activation of the hepatic-vagus pathway [24] contributes to the increase of pancreatic BCM and islet number in HSDT-fed mice, should be investigated in future study.

It is reported that switching from HFD to a low-fat diet (LFD) is effective in reducing body weight and improving glucose tolerance in obese mice after long-term exposure to HFD [25-27]. In addition, switching from HFD to LFD for 4 weeks normalizes glucose tolerance due to improved GIIS in mice fed HFD for 18 months, although the effect on body weight is comparatively small [25]. The morphology of islets was not been investigated in these reports [25-27]. We expected that switching from HSTD to NC in mice fed HSTD for 5 weeks would improve glucose tolerance in the presence of sustained increase in BCM and islet number. However, switching from HSTD to NC for 2 weeks in mice fed HSTD for 5 weeks reversed BCM and islet number to a level equal to that in mice fed NC, and did not alter glucose tolerance. These data suggest that $\mathrm{BCM}$ and islet number are regulated by nutrients rather than by a change of body weight or glucose metabolism. The mechanism of reducing BCM and islet number by switching from HSTD to NC for 2 weeks, and the extent of the involvement of nutrients in the regulation of BCM and islet number in humans, should be investigated in a future study. One limitation of the present study is that the effect of increased starch intake was inevitably 
combined with that of decreased protein intake. Laeger $\mathrm{T}$ et al. reported that low-protein diets increase the production and plasma concentration of fibroblast growth factor 21 (FGF21). FGF21 is known to enhance insulin sensitivity through increasing glucose uptake into peripheral tissue [28,29]. Thus, not only a starch-rich diet, but also the reduced protein intake may have contributed to the increased insulin sensitivity found in this study. Another limitation of the present study is that food consumption in mice was not evaluated. Food intake was increased in HSTD-fed mice, compared with that in NC-fed mice 15 weeks after intervention of diet in our previous study [5]. Thus, a difference in food intake may have had some effect on islet morphology.

A third limitation of the present study is that we did not take account of differences in vitamins, mineral premixes, fiber types, and the amount of fiber in NC and HSTD. Such differences may have affected the microbiome and absorption of nutrients in the intestine [30].

\section{Conclusions}

We investigated the effects of short-term high-starch diet on glucose metabolism and islet morphology. We find that a short-term, high-starch diet increases $\beta$-cell mass and islet number concomitantly with increased expression levels of cyclin A2 and irs 2 mRNA in islets. These changes occurred before changes in blood glucose levels and body weight appeared. Furthermore, switching from the high-starch diet to normal chow for 2 weeks after exposure to this high-starch diet for 5 weeks reversed the $\beta$-cell mass and islet number, without altering glucose-induced insulin secretion or body weight.

Author Contributions: The authors' contributions were as follows: A.M., Y.S. (Yusuke Seino), M.M., S.H., Y.S. (Yoshihisa Sugimura), Y.H., and A.S. participated in the research design. A.M., Y.S. (Yusuke Seino), M.M., and S.H. conducted these experiments. A.M., Y.S. (Yusuke Seino), and A.S. wrote the manuscript. A.M., Y.S. (Yusuke Seino), M.M., S.H., M.S., T.T., Y.S. (Yoshihisa Sugimura), Y.H., and A.S. contributed to discussion. A.M., Y.S. (Yusuke Seino), M.S., T.T., Y.S. (Yoshihisa Sugimura), Y.H., and A.S. reviewed and edited the manuscript. All authors gave approval of the final version to be published. Y.S. (Yusuke Seino) is the guarantor of this work and had full access to all the data in the study and takes responsibility for the integrity of data and the accuracy of data analysis.

Funding: This study was supported by grants from Grants-in-Aid for Scientific Research from Japan Society for the Promotion of Science to Y.S. (Yusuke Seino). (17k09823) and research grants from Novo Nordisk Pharma Ltd., MSD K.K., Pfizer., Mitsubishi Tanabe Pharma., Eli Lilly and Company., Novartis Pharma., and Daiichi Sankyo Company Ltd.

Acknowledgments: The authors thank Mika Maejima (Fujita Health University) for technical assistance and Nagoya University stuff for technical assistance and suggestions.

Conflicts of Interest: The authors declare no conflict of interest.

\section{References}

1. Seino, S.; Sugawara, K.; Yokoi, N.; Takahashi, H. $\beta$-Cell signalling and insulin secretagogues: A path for improved diabetes therapy. Diabetes Obes. Metab. 2017, 19, 22-29. [CrossRef]

2. Mehran, A.E.; Templeman, N.M.; Brigidi, G.S.; Lim, G.E.; Chu, K.Y.; Hu, X.; Botezelli, J.D.; Asadi, A.; Hoffman, B.G.; Kieffer, T.J.; et al. Hyperinsulinemia Drives Diet-Induced Obesity Independently of Brain Insulin Production. Cell Metab. 2012, 16, 723-737. [CrossRef] [PubMed]

3. Blüher, M.; Dodson Michael, M.; Peroni, O.D.; Ueki, K.; Carter, N.; Kahn, B.B.; Ronald Kahn, C. Adipose Tissue Selective Insulin Receptor Knockout Protects against Obesity and Obesity-Related Glucose Intolerance insulin resistance, moderate glucose intolerance, and a failure of insulin to suppress hepatic glucose production and regulate hepatic gene. Dev. Cell 2002, 3, 25-38. [CrossRef]

4. Miyawaki, K.; Yamada, Y.; Ban, N.; Ihara, Y.; Tsukiyama, K.; Zhou, H.; Fujimoto, S.; Oku, A.; Tsuda, K.; Toyokuni, S.; et al. Inhibition of gastric inhibitory polypeptide signaling prevents obesity. Nat. Med. 2002, 8, 738-742. [CrossRef] [PubMed]

5. Maekawa, R.; Ogata, H.; Murase, M.; Harada, N.; Suzuki, K.; Joo, E.; Sankoda, A.; Iida, A.; Izumoto, T.; Tsunekawa, S.; et al. Glucose-dependent insulinotropic polypeptide is required for moderate high-fat dietbut not high-carbohydrate diet-induced weight gain. Am. J. Physiol. Metab. 2018, 314, E572-E583. [CrossRef] [PubMed] 
6. Nasteska, D.; Harada, N.; Suzuki, K.; Yamane, S.; Hamasaki, A.; Joo, E.; Iwasaki, K.; Shibue, K.; Harada, T.; Inagaki, N. Chronic Reduction of GIP Secretion Alleviates Obesity and Insulin Resistance Under High-Fat Diet Conditions. Diabetes 2014, 63, 2332-2343. [CrossRef]

7. Murase, M.; Seino, Y.; Maekawa, R.; Iida, A.; Hosokawa, K.; Hayami, T.; Tsunekawa, S.; Hamada, Y.; Yokoi, N.; Seino, S.; et al. Functional adenosine triphosphate-sensitive potassium channel is required in high-carbohydrate diet-induced increase in $\beta$-cell mass. J. Diabetes Investig. 2019, 10, 238-250. [CrossRef]

8. Butler, A.E.; Janson, J.; Soeller, W.C.; Butler, P.C. Increased beta-cell apoptosis prevents adaptive increase in beta-cell mass in mouse model of type 2 diabetes: evidence for role of islet amyloid formation rather than direct action of amyloid. Diabetes 2003, 52, 2304-2314. [CrossRef]

9. Saisho, Y.; Butler, A.E.; Manesso, E.; Elashoff, D.; Rizza, R.A.; Butler, P.C. $\beta$-Cell Mass and Turnover in Humans: Effects of obesity and aging. Diabetes Care 2013, 36, 111-117. [CrossRef]

10. Maekawa, R.; Seino, Y.; Ogata, H.; Murase, M.; Iida, A.; Hosokawa, K.; Joo, E.; Harada, N.; Tsunekawa, S.; Hamada, Y.; et al. Chronic high-sucrose diet increases fibroblast growth factor 21 production and energy expenditure in mice. J. Nutr. Biochem. 2017, 49, 71-79. [CrossRef] [PubMed]

11. Niwa, Y.; Ishikawa, K.; Ishigami, M.; Honda, T.; Achiwa, K.; Izumoto, T.; Maekawa, R.; Hosokawa, K.; Iida, A.; Seino, Y.; et al. Effect of hyperglycemia on hepatocellular carcinoma development in diabetes. Biochem. Biophys. Res. Commun. 2015, 463, 344-350. [CrossRef]

12. Fukami, A.; Seino, Y.; Ozaki, N.; Yamamoto, M.; Sugiyama, C.; Sakamoto-Miura, E.; Himeno, T.; Takagishi, Y.; Tsunekawa, S.; Ali, S.; et al. Ectopic Expression of GIP in Pancreatic $\beta$-Cells Maintains Enhanced Insulin Secretion in Mice With Complete Absence of Proglucagon-Derived Peptides. Diabetes 2013, 62, 510-518. [CrossRef]

13. Bonner-Weir, S.; Deery, D.; Leahy, J.L.; Weir, G.C. Compensatory growth of pancreatic beta-cells in adult rats after short-term glucose infusion. Diabetes 1989, 38, 49-53. [CrossRef]

14. Lipsett, M.; Finegood, D.T. B-Cell Neogenesis during Prolonged Hyperglycemia in Rats. Diabetes 2002, 51, 1834-1841. [CrossRef]

15. Jetton, T.L.; Everill, B.; Lausier, J.; Roskens, V.; Habibovic, A.; LaRock, K.; Gokin, A.; Peshavaria, M.; Leahy, J.L. Enhanced beta-cell mass without increased proliferation following chronic mild glucose infusion. Am. J. Physiol. Endocrinol. Metab. 2008, 294, E679-E687. [CrossRef]

16. Moullé, V.S.; Vivot, K.; Tremblay, C.; Zarrouki, B.; Ghislain, J.; Poitout, V. Glucose and fatty acids synergistically and reversibly promote beta cell proliferation in rats. Diabetologia 2017, 60, 879-888. [CrossRef]

17. Hull, R.L.; Kodama, K.; Utzschneider, K.M.; Carr, D.B.; Prigeon, R.L.; Kahn, S.E. Dietary-fat-induced obesity in mice results in beta cell hyperplasia but not increased insulin release: Evidence for specificity of impaired beta cell adaptation. Diabetologia 2005, 48, 1350-1358. [CrossRef]

18. Terauchi, Y.; Takamoto, I.; Kubota, N.; Matsui, J.; Suzuki, R.; Komeda, K.; Hara, A.; Toyoda, Y.; Miwa, I.; Aizawa, S.; et al. Glucokinase and IRS-2 are required for compensatory $\beta$ cell hyperplasia in response to high-fat diet-induced insulin resistance. J. Clin. Investig. 2007, 117, 246-257. [CrossRef]

19. Tajima, K.; Shirakawa, J.; Okuyama, T.; Kyohara, M.; Yamazaki, S.; Togashi, Y.; Terauchi, Y. Effects of metformin on compensatory pancreatic $\beta$-cell hyperplasia in mice fed a high-fat diet. Am. J. Physiol. Metab. 2017, 313, E149-E159. [CrossRef]

20. Mosser, R.E.; Maulis, M.F.; Moullé, V.S.; Dunn, J.C.; Carboneau, B.A.; Arasi, K.; Pappan, K.; Poitout, V.; Gannon, M. High-fat diet-induced $\beta$-cell proliferation occurs prior to insulin resistance in C57Bl/6J male mice. Am. J. Physiol. Metab. 2015, 308, E573-E582. [CrossRef]

21. Stamateris, R.E.; Sharma, R.B.; Hollern, D.A.; Alonso, L.C. Adaptive $\beta$-cell proliferation increases early in high-fat feeding in mice, concurrent with metabolic changes, with induction of islet cyclin D2 expression. Am. J. Physiol. Metab. 2013, 305, E149-E159. [CrossRef]

22. Kitao, N.; Nakamura, A.; Miyoshi, H.; Nomoto, H.; Takahashi, K.; Omori, K.; Yamamoto, K.; Cho, K.Y.; Terauchi, Y.; Atsumi, T. The role of glucokinase and insulin receptor substrate-2 in the proliferation of pancreatic beta cells induced by short-term high-fat diet feeding in mice. Metabolism 2018, 85, 48-58. [CrossRef]

23. Georgia, S.; Hinault, C.; Kawamori, D.; Hu, J.; Meyer, J.; Kanji, M.; Bhushan, A.; Kulkarni, R.N. Cyclin D2 is essential for the compensatory $\beta$-cell hyperplastic response to insulin resistance in Rodents. Diabetes 2010, 59, 987-996. [CrossRef] 
24. Imai, J.; Katagiri, H.; Yamada, T.; Ishigaki, Y.; Suzuki, T.; Kudo, H.; Uno, K.; Hasegawa, Y.; Gao, J.; Kaneko, K.; et al. Regulation of Pancreatic b Cell Mass by Neuronal Signals from the Liver. Science 2008, 322, 1250-1254. [CrossRef]

25. Agardh, C.-D.; Ahrén, B. Switching from high-fat to low-fat diet normalizes glucose metabolism and improves glucose-stimulated insulin secretion and insulin sensitivity but not body weight in C57BL/6 $\mathrm{J}$ mice. Pancreas 2012, 41, 253-257. [CrossRef]

26. Parekh, P.I.; Tiller, J.M.; Feinglos, M.N.; Design, E.; Sciences, B.; Sciences, H. Reversal of Diet-Induced Obesity and Diabetes in C57BL/6J Mice. Metabolism 1998, 9, 1089-1096. [CrossRef]

27. Kowalski, G.M.; Hamley, S.; Selathurai, A.; Kloehn, J.; De Souza, D.P.; O'Callaghan, S.; Nijagal, B.; Tull, D.L.; McConville, M.J.; Bruce, C.R. Reversing diet-induced metabolic dysregulation by diet switching leads to altered hepatic de novo lipogenesis and glycerolipid synthesis. Sci. Rep. 2016, 6, 1-10. [CrossRef]

28. Kim, J.; Bae, K.; Choi, Y.; Go, Y.; Choe, M.; Jeon, Y.; Lee, H.; Koo, S.; Perfield, J.W.; Harris, R.A.; et al. Fibroblast growth factor 21 analogue LY2405319 lowers blood glucose in streptozotocin-induced insulin-deficient diabetic mice by restoring brown adipose tissue function. Diabetes Obes. Metab. 2015, 161-169. [CrossRef]

29. Laeger, T.; Henagan, T.M.; Albarado, D.C.; Redman, L.M.; Bray, G.A.; Noland, R.C.; Münzberg, H.; Hutson, S.M.; Gettys, T.W.; Morrison, C.D.; et al. FGF21 is an endocrine signal of protein restriction. J. Clin. Investig. 2014, 124, 3913-3922. [CrossRef]

30. Pellizzon, M.A.; Ricci, M.R. The common use of improper control diets in diet-induced metabolic disease research confounds data interpretation: The fiber factor. Nutr. Metab. 2018, 15, 1-6.

(C) 2019 by the authors. Licensee MDPI, Basel, Switzerland. This article is an open access article distributed under the terms and conditions of the Creative Commons Attribution (CC BY) license (http://creativecommons.org/licenses/by/4.0/). 